\title{
PROGRESSIVE PRIMARY FORM OF MULTIPLE SCLEROSIS
}

\section{Clinical and radiological improvement with methylprednisolone in continuous pulsetherapy in one case for 16 years}

\author{
Edmar A.S. Araujo, Marcos R.G. de Freitas', Alair Augusto S.M.D. Santos ${ }^{2}$, Marcos Antonio Araújo'
}

Multiple sclerosis (MS) might be considered as a disease with different clinical phenotypes. Approximately $10-15 \%$ of the patients have the primary progressive form (PPMS). Confavreux and Vukusic considered PPMS as a multiple sclerosis 'amputated' from the usual preceding relapsing-remitting phase, saying it as one disease with different clinical phenotypes rather than an entity encompassing several distinct diseases'. The treatment of MS is directly based in animals' models. However there are no proven benefits in humans ${ }^{2}$. The inflammatory nature of MS suggests that endogenous cortisol, which is under control of the hypothalamus-pituitary-adrenal (HPA) axis, plays a role in the course and susceptibility of MS. Insensitivity to glucocorticoids might lead to enhanced inflammation in MS, whereas hyperactivity of the HPA axis has been linked to neurodegeneration and increase disability. Variability in the glucocorticoid receptor gene is a potential explanation for differences in glucocorticoids sensitivity and may influence the disease course ${ }^{3}$. We have shown the benefit of methylprednisolone in continuous pulse therapy (IVMP) in PPMS ${ }^{4}$. The improvement of the clinical course and radiological findings in one patient of our group with the PPMS form motivated us to relate this case.

\section{CASE}

A 38 year-old woman was admitted in 1992, and her disease initiated 13 year ago with a slowing progressive difficult to walk, incoordination in upper limbs and urinary incontinence for fourteen years. She had spastic paraplegia, brisk tendon reflexes, bilateral Babinski signs, decreased vibratory sensation in lower limbs, tremor and dysmetria in upper limbs and a left deafferenteted pupil. We excluded Vit B12 deficiency, syphilis, schistosomiasis, HIV, HTLV1 and 2, degenerative diseases, cervical spondilosis and others. The spinal fluid showed an elevated IgG index. She presented PPMS, according to McDonald's criteria ${ }^{5}$. The EDDS $^{6}$ score was 6 (ability to walk with unilateral support no more than $100 \mathrm{~m}$ without rest). Treatment consists of continuous IVMP as we related in our protocol ${ }^{4}$. The patient agreed with this kind of treatment signing an informed consent. The EDDS score and the periodicity of IVMP was evaluated in each year (Table). Actually she has mild paraparesis, and is neurological stable since 2004: she walks without aid, there is no incoordination in upper limbs and no urinary incontinence (EDSS 3). Comparing brain MRI in the course of the disease, in 2007 there is a lower number of high signals in periventricular white matter (Fig 1A,B); there was no gadolinium enhancement in frontal lobe in 2007 comparing to 1995 (Fig 2A,B). In 2007 there was reduction of brain atrophy (Fig $3 \mathrm{~A}, \mathrm{~B})$.

\section{DISCUSSION}

There is no approved treatment for the PPMS. Nevertheless, some important clinical benefits have been observed after treatment in progressive forms with highdose methylprednisolone alone $e^{4,7,8}$ or with cyclophosphamide. There is consensus that IVMP is considered the

Table. EDDS evolution in course of treatment.

\begin{tabular}{lccccc}
\hline Year & 1992 & 1994 & 1996 & $1998-2002$ & $2004-2008$ \\
\hline EDDS & 6 & 5 & 4 & 4 & 3 \\
IV MP (intervals of days) & 10 & 20 & 20 & 30 & 40 \\
\hline
\end{tabular}

IVMP: intravenous methylprednosolone

\section{FORMA PROGRESSIVA PRIMÁRIA DA ESCLEROSE MÚLTIPLA: MELHORA CLÍNICA E RADIOLÓGICA COM PULSOTERAPIA CONTÍNUA COM METIL- PREDNISOLONA EM UM CASO POR 16 ANOS}

${ }^{1}$ Neuroimmunoly Unit, Neurological Service, ${ }^{2}$ Radiological Unit, Hospital Universitário Antonio Pedro, Universidade Federal Fluminense, Niterói RJ, Brazil.

Received 25 September 2008, received in final form 9 February 2009. Accepted 27 April 2009.

Dr. Edmar A.S. de Araujo - Avenida Paulo de Melo Kale 684 - 24350-030 Niterói RJ - Brasil. E-mail: edmardearaujo2@yahoo.com.br 


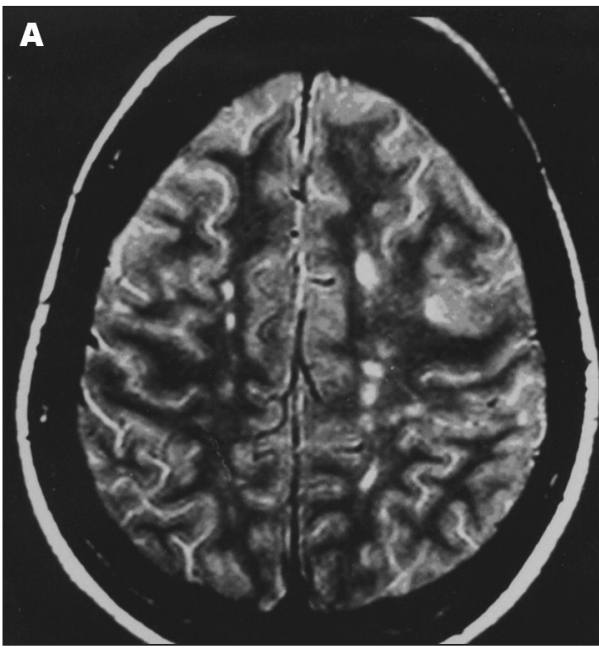

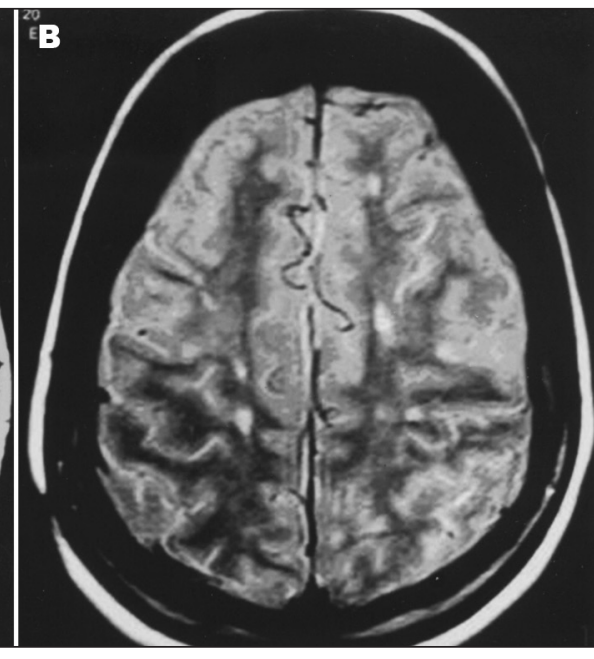

Fig 1. Axial T2 weighted MRI. [A] Multiple plaques in the white matter $A$ (1996). [B] Slight improvement of high signals in periventricular white mat$\operatorname{ter}(2005)$.

Fig 2. Coronal post-contrast T7-weight image. [A] An enhancing small lesion in the left frontal lobe due to disruption of the blood-brain barrier (1997). [B] 2006: there is no enhancement.
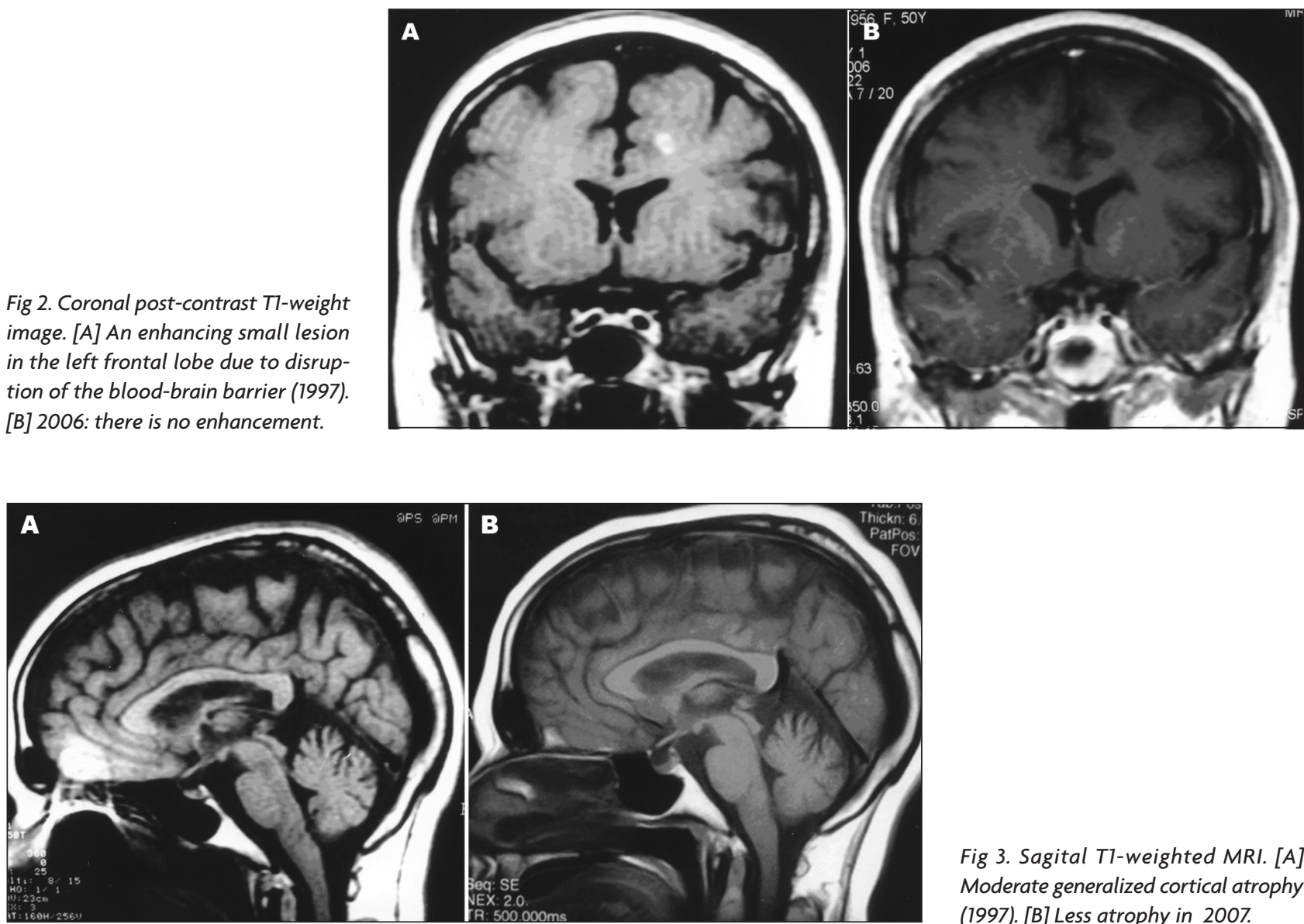

Fig 3. Sagital T1-weighted MRI. [A] Moderate generalized cortical atrophy (1997). [B] Less atrophy in 2007.

standard treatment for relapses in MS and prevents or delays disability progression ${ }^{10}$ and brain MRI showing less $\mathrm{T1}$ black roles, with less marked atrophy and few gadolinium enhancements ${ }^{10,11}$.

Our patient presents PPMS, according to McDonald's criteria ${ }^{5}$. Initially she hardly walked alone, and the EDDS was 6. After continuous IVMP there was improvement in the next years. In 2004 she became stable. Actually she walks alone, without cerebellar and sphincter disturbances with mild paraparesis. There was no inccoordination in upper limbs and no urinary incontinence. The initial EDSS that were 6 improved to 3.

Comparing the initials MRI (1996 and 1997) with the latest ones (2005, 2006 and 2007) there is some improvement in the lesions. The number of the multiple bright signals is lower in the white matter (Fig $1 \mathrm{~A}, \mathrm{~B}$ ), there is no more 
post-contrast enhancement (Fig 2A,B) and the diffuse cortical atrophy seen in 1996 became less marked (Fig 3A,B).

In our case the continuation of IVMP therapy maintained the previously acquired clinical benefits. There are few undesirable or collateral effects concerning to the chronic use of IVMP. We concluded that continuous IVMP may be one kind of treatment for PPMS and that is necessary a multicentric study with this therapy.

\section{REFERENCES}

1. Confavreux C, Vukusic S. Natural history of multiple sclerosis: a unifying concept. Brain 2006;129:606-616.

2. Holmey T, Vartdal F. The immunological basis for treatment of multiple sclerosis. Scand J Immunol 2007;66:374-382.

3. Van Vinsen LML, Hooner-van Veen T, van Rossum EFC, et al. Glucocorticoid receptor gene polymorphism associated with more aggressive disease phenotype in MS. J Neuroimmunol 2007;186:150-155.

4. Araújo EA, de Freitas MRG. Benefit with methylprednisolone in continuous pulsetherapy in progressive primary form of multiple sclerosis. Arq Neuropsiquiatr 2008;66:350-353.

5. Mc Donald WI, Compston A, Edan G,, et al. Recommended diagnostic criteria for multiple sclerosis: guidelines from the in- ternational panel on the diagnosis of multiple sclerosis. Ann Neurol 2001;50:121-127.

6. Kurtzke JF. Rating neurologic impairment in multiple sclerosis: an expanded disability status scale (EDSS). Neurology 1983; 33:1444-1452.

7. Goodkin DE, Kinkel RP, Weinstock-Guttman B, et al. A phase II study of IV methylprednisolone in secondary-progressive multiple sclerosis. Neurology 1998;51:239-245.

8. Cazzato G, Mesiano T, Antonello R, et al. Double-blind, placebo-controlled, randomized, crossover trial of high-dose methylprednisolone in patients with chronic progressive form of multiple sclerosis. Eur Neurol 1995;35:193-198.

9. Zephir H, de Seze J, Duhamel A, et al. Treatment of progressive forms of multiple sclerosis by cyclophosphamide: a cohort study of 490 patients. J Neurol Sci 2004;218:73-77.

10. Zivadinov R, Rudick RA, De Masi R, et al. Effects of IV methilprednisolone on brain atrophy in relapsing-remitting MS. Neurology 2001;57:1239-1247.

11. Then Bergh F, Kumpfel T, Schumann E, et al. Monthly intravenous methylprednisolone in relapsing-remitting multiple sclerosis-reduction of enhancing lesions, T2 lesion volume and plasma prolactin concentrations. BMC Neurol 2006;23:6-19.Table 1- EDDS evolution in course of treatment. 